\title{
Economic Order Quantity Model of Aircraft Turnover Parts in Aviation Industry
}

\author{
Chaofeng Wang *, Yamiao Wen \\ School of Airport Engineering \& Transportation Management, Civil Aviation Flight University of China, \\ Guanghan, Sichuan, China \\ *Corresponding Author.
}

\begin{abstract}
The inventory control of turnover parts is the key and difficult point for aircraft spare parts management, which is directly related to the benefit level of airlines in aviation industry. On the basis of considering the depreciation cost, repair cost, inventory cost and shortage cost, this paper analyzes the annual replacement times and turnover cycle, and puts forward the optimization model of Economic Order Quantity (EOQ) of aircraft turnover parts. The feasibility of the method is verified by an example. Through sensitivity analysis, it is concluded that the strong sensitive factors affecting EOQ are annual replacement times and unit shortage cost, while the purchase price has little influence on EOQ.
\end{abstract}

Keywords : Aviation Industry, turnover part, EOQ, inventory control, aircraft spare parts

\section{Introduction}

With the rapid development of the national economy and the increasingly close international exchanges, air transport continues to develop rapidly. As more and more participants enter the civil aviation industry, the competition in the air transportation market becomes more and more fierce, the economic benefits of airlines are generally low, and the operating pressure increases. As for the cost of airlines, aviation oil cost and route cost account for a large proportion, but they are uncontrollable costs, while other costs account for a small proportion, which has little impact on the operation. Aircraft parts holding cost takes up a large proportion of working capital and the turnover is slow, which has optimization space to be studied. It has gradually been concerned by airlines, making it an effective way to reduce costs and improve efficiency. In the aircraft spare parts reserve, $80 \%$ of the inventory comes from the turnover parts, especially the larger the fleet, the more the quantity of aircraft parts ordered, the higher the procurement cost and maintenance management cost.

If the inventory of turnover parts is insufficient to meet the requirements of normal flight, it may cause the aircraft to fail to operate normally. On the contrary, if the inventory of turnover parts is too much, the turnover speed is slow, and a large amount of funds become idle, it causes airlines to suffer losses. At the same time, some turnover parts have the requirements of service life and technical renewal, which not be handled for a long time, and also easily cause economic losses. Therefore, a scientific and reasonable procurement plan for turnover parts and the targeted application of economic order quantity model are conducive to keeping the inventory of turnover parts at a reasonable level, so as to ensure the continuous airworthiness of aircraft and reduce costs. It not only meets the needs of safe flight of aircraft, but also optimizes the profitability of aviation companies.

The importance of aircraft parts inventory management for airline production and operation has been recognized at home and abroad for a long time. Researchers have been exploring how to meet the inventory demand, improve the inventory guarantee rate and improve the inventory turnover rate to reduce the inventory cost. At present, the research on aircraft spare parts is mostly based on certain assumptions of demand, or for a certain kind of demand. Mabini and Christer proposed a model to determine the inventory level of repairable aircraft spare parts with low

ISSN: 0010-8189 
demand and high cost [1]. Fritzsche proposed a cost estimation and analysis model based on (S-1, S) inventory strategy for many high value aircraft parts [2]. Sun and Zuo formed a multi objective and multi-level aircraft parts inventory level determination model based on system method [3]. Sherbrooke proposed that for the high cost and low demand aircraft parts, the appropriate strategy is $(\mathrm{s}-1, \mathrm{~s})$, that is, not to use the batch reorder [4]. Basten, Heijden and Schutten proposed a joint inventory optimization strategy based on maintenance analysis [5]. Wong, Houtum, Cattrysse and Oudheusden studied a multi item, continuous repairable spare parts inventory system model [6].

Due to the large amount of aircraft parts warehouse and complex organization setting, the feasibility of its system completely reconstruction is low. Many studies are aimed at a specific airline or maintenance base to put forward optimization schemes and strategies. Rezaei, Baboli, Shahzad and Tonadre, taking the business aircraft company as an example, studied a new method to optimize the target inventory level under the condition of unpredictable spare parts demand [7]. Costantino, Gravio and Tronci proposed an innovative parts allocation model for the spare parts reserve of the Italian air force, which aims to minimize the delayed orders and improve the support rate to 99\% [8]. Yan optimized the inventory management of DH airline aircraft parts [9]. Lu studied the optimization of SC airline aircraft spare parts supply management [10]. Liang studied the optimization of the inventory management of aircraft parts of XX Airlines [11]. Song optimized the aircraft parts support of Air China maintenance base [12].

In the research of existing literature, we can see that the current research on the inventory of aircraft parts is mainly from the perspective of inventory optimization methods or allocation. However, in the quantitative study of the optimization of the aircraft parts, especially the turnover parts, the shortage cost of the turnover parts is not considered. As we all know, the impact of shortage of different aircraft turnover parts on flight is different, and the cost of shortage is different. In this context, the problem of shortage of spare parts is not considered, but it is very important in the process of ordering and inventory control of aircraft parts. Based on this, based on the consideration of the shortage cost of the turnover parts, this paper proposes the EOQ model of the aircraft turnover parts, and optimizes the order and inventory strategy of the turnover parts.

\section{Analysis of Factors Affecting EOQ}

The direct influence factor of Economic Order Quantity (EOQ) is the demand per unit time. The demand for aircraft turnover parts is mainly affected by two factors: on the one hand, the consumption of aircraft spare parts is directly triggered by maintenance and replacement, which is related to the times of disassembly and replacement in unit time; on the other hand, because the parts can be used repeatedly after repair, it is related to the time of repair and turnover.

\subsection{Annual replacement times}

According to the aircraft failure mode, it is found that about $11 \%$ of the components have definite life limit, which can be made accurate maintenance or replacement plan, while the remaining $89 \%$ of the components have to be used until the failure occurs, which could not be made accurate replacement plans. Therefore, the annual replacement times can be divided into two cases: deterministic demand and uncertain demand. In terms of expression, the following formula can be used to calculate the annual replacement times, $\mathrm{R}$.

$$
\mathrm{R}=\frac{n \times m \times F L}{t}
$$

Where, $\mathrm{n}$ is the number of aircraft, $\mathrm{m}$ is the number of aircraft parts transferred by a single aircraft, and FL is the annual flight hours of a single aircraft. For the turnover parts with deterministic demand, $t$ is the maintenance interval; For the turnover parts with uncertain demand, $t$ is the mean time between unscheduled removals.

\subsection{Turnover time}

Turnover time refers to all the time that turnover parts are removed from the aircraft after failure, and then put back into storage and become usable parts after repair, domestic and foreign transportation. Turnover time, $T A T$, can be obtained according to the statistics of the average repair time.

ISSN: 0010-8189 


\subsection{Consumption quantity of aircraft spare parts}

The consumption quantity of aircraft parts refers to the quantity of aircraft parts required in a certain period of time. On the basis of considering the annual replacement times and turnover time, the annual consumption quantity of turnover parts, $\mathrm{m}$, can be obtained.

$$
\mathrm{m}=\mathrm{R} \times \frac{T A T}{365}
$$

\section{Basic Hypothesis and Symbol Description}

\subsection{Basic hypothesis}

The model and analysis are based on the following assumptions.

(1) The turnover parts can be used repeatedly, and their service life is consistent with the engine, propeller or aircraft body they serve;

(2) The consumption law of turnover parts can be obtained by statistics;

(3) The demand probability of turnover parts is constant;

(4) In the two periods of non-overlapping time, the demand times of turnover parts are independent of each other;

(5) In a period of time, the demand times of turnover parts have nothing to do with the starting point of the time period, but only with the length of the time period;

(6) The average repair cycle of turnover parts can be obtained;

(7) Unit repair cost and unit shortage cost of turnover parts can be obtained.

\subsection{Symbol description}

The parameter symbols defined in the model are as follows.

TC: Annual total cost;

C1: Depreciation cost;

C2: Repair cost;

C3: Inventory cost;

C4: Shortage cost;

$\mathrm{R}$ : Annual average times of replacement

$\mathrm{m}$ : Annual average consumption amount;

Q: Order quantity;

$\eta$ : Guarantee rate;

B: Depreciation rate;

F: Fixed repair cost;

A: Variable cost of single repair;

Y: Unit shortage cost;

$\mathrm{K} 1$ : Inventory rate;

$\mathrm{K} 2$ : Value added tax rate;

K3: Tariff rate;

U: Service life of turnover parts;

$\mathrm{P}(\mathrm{Q})$ : the probability of consuming $\mathrm{Q}$ when the average consumption of turnover parts is $\mathrm{m}$.

\section{Modelling}

\subsection{Object function}

ISSN: 0010-8189

(C) CONVERTER 2020 
The total cost of aircraft turnover parts in order cycle consists of depreciation cost, repair cost, inventory cost and shortage cost. The objective function is to minimize the total cost of turnover parts inventory. The object cost function is as follows.

$$
\operatorname{Min} \mathrm{TC}=C_{1}+C_{2}+C_{3}+C_{4}
$$

4.1.1 Depreciation cost

The depreciation cost is the annual apportioned cost of the purchase cost over the service life.

$$
C_{1}=B \times Q
$$

\subsubsection{Repair cost}

The repair cost refers to the total cost of the aircraft parts to be replaced, which is the sum of the fixed repair cost and the variable repair cost. The variable repair cost is the product of annual repair times and single repair cost. The repair of aircraft turnover parts mostly involves import and export, so the influence of value-added tax and tariff should be considered.

$$
C_{2}=F+\frac{R}{Q} \times A \times\left(1+K_{2}\right)
$$

\subsubsection{Inventory cost}

Inventory cost refers to the cost of keeping and managing inventory.

$$
C_{3}=\frac{B \times Q \times\left(1+K_{1}\right)}{2}
$$

\subsubsection{Shortage cost}

Shortage cost refers to the loss caused by aircraft delay or even parking due to the delayed supply of turnover parts, and also includes the cost of emergency goods transfer.

$$
\mathrm{C}_{4}=[1-\eta(q)] \times \mathrm{Q} \times Y
$$

To sum up, the total annual cost of turnover parts is the sum of depreciation cost, repair cost, inventory cost and shortage cost.

$$
\operatorname{MinTC}=\mathrm{B} \times \mathrm{D}+\mathrm{F}+\frac{R}{Q} \times A \times\left(1+K_{2}\right)+\frac{B \times Q \times\left(1+K_{1}\right)}{2}+[1-\eta(q)] \times Q \times Y
$$

\subsection{Solution method}

(1) The average demand of aircraft turnover parts, $\mathrm{m}$, is calculated by obtaining the data of annual replacement times and turnover time.

(2) Analyze the consumption rule of turnover parts. As most of the consumption of aircraft turnover parts obey Poisson distribution, Poisson distribution is taken as an example to analyze. Through the formula, $p(Q)=$ $\frac{m^{Q}}{Q !} e^{-m}(Q=0,1,2 \ldots, n)$, we get the probability about the average consumption of turnover parts, $Q$, when the average consumption is $\mathrm{m}$, and then calculate the guarantee rate, $\eta=\sum_{\mathrm{q}=0}^{\mathrm{R}} \mathrm{p}(\mathrm{Q})$, of different $\mathrm{Q}$.

(3) The total inventory cost, TC, corresponding to different order quantity, Q, is calculated.

(4) By sorting and comparing the total cost of turnover parts, the minimum total inventory cost is selected, and the corresponding order quantity is the Economic Order Quantity (EOQ).

\section{V.Case Analysis}

ISSN: 0010-8189 


\subsection{Case calculation}

The monthly consumption of a certain turnover part of an airline from January 2016 to December 2019 is shown in Table 1.

Table 1 Monthly consumption of a certain turnover part from Jan. 2016 to Dec 2019.

\begin{tabular}{|c|c|c|c|c|c|c|c|c|c|c|c|c|}
\hline Year & Jan. & Feb. & Mar. & Apr. & May. & Jun. & Jul. & Aug & Sep. & Oct. & Nov. & Dec. \\
\hline 2016 & 2 & 3 & 1 & 2 & 2 & 1 & 0 & 1 & 1 & 2 & 1 & 2 \\
\hline 2017 & 1 & 1 & 2 & 2 & 2 & 1 & 1 & 2 & 3 & 1 & 2 & 1 \\
\hline 2018 & 1 & 2 & 2 & 1 & 1 & 3 & 1 & 0 & 2 & 1 & 1 & 2 \\
\hline 2019 & 3 & 1 & 1 & 1 & 2 & 1 & 2 & 2 & 2 & 1 & 0 & 2 \\
\hline
\end{tabular}

The data comes from the historical consumption records of a turnover part of 737 aircraft of an airline.

(1) According to the historical consumption data of the airline in four years, the total number of replacement in 2016 is $\mathrm{R} 1=18$, and the same data in 2017 is $\mathrm{R} 2=19$, in 2018 is $\mathrm{R} 3=17$, in 2019 is $\mathrm{R} 4=18$.

Through the simple moving average method, the annual average number of replacement, $\mathrm{R}=18+19+17+18) / 4$ $=18$. As the average repair period of the turnover parts is 60 days, the average consumption amount in the period is, $\mathrm{m}=18 \times 60 / 365=2.96 \approx 3$.

(2) When $\mathrm{m}=3$, the guarantee rate, $\eta$, with different consumption is calculated. The results are shown in the column of guarantee rate in Table 2.

(3) According to the data of aircraft parts management, the planned unit price of the new turnover part is 613500 US dollars. Considering the 10-year service life, that is, the annual depreciation cost of a single turnover part is 61350 US dollars, the single comprehensive repair cost is $15 \%$ of the annual depreciation cost, that is 9202.5 US dollars, and the fixed cost of the repair cost is 200000 RMB yuan. Suppose that the inventory rate of the turnover parts is $10 \%$ of the annual depreciation cost, the shortage cost is $50 \%$ of the annual depreciation cost, the exchange rate is 6.6 , the value-added tax rate is $16 \%$, and the tariff rate is $10 \%$. The calculation results of $\mathrm{C} 1, \mathrm{C} 2, \mathrm{C} 3, \mathrm{C} 4$ and $\mathrm{C}$ are shown in Table 2 and figure 1.

Table 2 Aircraft parts inventory cost calculation

(Unit: RMB million yuan)

\begin{tabular}{|c|c|c|c|c|c|c|}
\hline $\begin{array}{c}\text { Order quantity } \\
(\mathrm{Q})\end{array}$ & $\begin{array}{c}\text { Guarantee rate } \\
(\eta)\end{array}$ & $\mathrm{C}_{1}$ & $\mathrm{C}_{2}$ & $\mathrm{C}_{3}$ & $\mathrm{C}_{4}$ & $\mathrm{TC}$ \\
\hline 0 & 0.050 & 0.00 & 0.20 & 0.00 & 3.463 & 3.66 \\
\hline 1 & 0.199 & 0.40 & 1.59 & 0.02 & 2.918 & 4.94 \\
\hline 2 & 0.423 & 0.81 & 0.90 & 0.04 & 2.102 & 3.85 \\
\hline 3 & 0.647 & 1.21 & 0.66 & 0.07 & 1.286 & 3.23 \\
\hline 4 & 0.815 & 1.62 & 0.55 & 0.09 & 0.673 & 2.93 \\
\hline 5 & 0.916 & 2.02 & 0.48 & 0.11 & 0.306 & 2.92 \\
\hline 6 & 0.966 & 2.43 & 0.43 & 0.13 & 0.122 & 3.12 \\
\hline 7 & 0.988 & 2.83 & 0.40 & 0.16 & 0.044 & 3.43 \\
\hline
\end{tabular}




\begin{tabular}{|c|c|c|c|c|c|c|}
8 & 0.996 & 3.24 & 0.37 & 0.18 & 0.014 & 3.81 \\
\hline 9 & 0.999 & 3.64 & 0.35 & 0.20 & 0.004 & 4.20 \\
\hline 10 & 1.000 & 4.05 & 0.34 & 0.22 & 0.001 & 4.61 \\
\hline 11 & 1.000 & 4.45 & 0.33 & 0.24 & 0.001 & 5.03 \\
\hline 12 & 1.000 & 4.86 & 0.32 & 0.27 & 0.001 & 5.44 \\
\hline
\end{tabular}

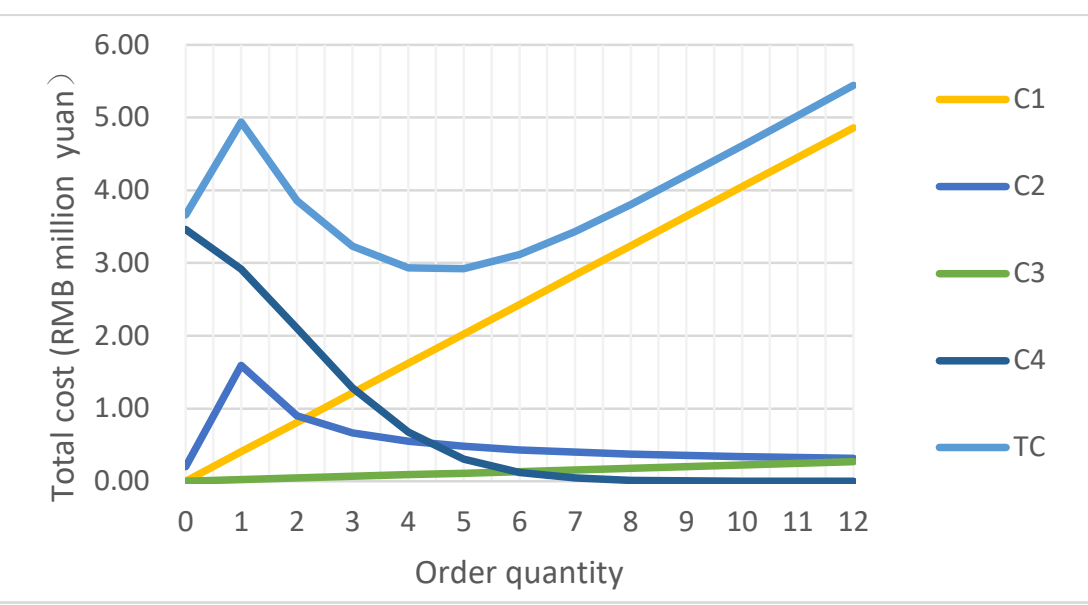

Fig 1: Change of aircraft parts inventory cost

(4) By sorting and comparing the total cost of turnover parts, the minimum total cost of inventory is selected. The corresponding order quantity is 5 , which is the optimal economic order quantity. The corresponding guarantee rate is $91.6 \%$, and the total cost is 2.921 million yuan.

\subsection{Sensitivity analysis}

In the total cost of turnover parts, the three factors that may have a great impact on EOQ are: the average annual Times of replacement, purchase unit price and shortage cost. Therefore, the sensitivity of these three factors were analyzed.

\subsubsection{Annual average times of replacement}

In Section 5.1, the average number of replacement is 18 , and the average annual consumption is 3. Assuming that the average annual replacement times are 6, 18,30, 60 and 90 respectively, the average annual consumption is 1, 3, 5, 10 and 15 respectively with other indexes unchanged. The optimal EOQ under different conditions is analyzed and calculated, as shown in Table 3 below.

Table 3 Influence of annual average number of replacement on EOQ

\begin{tabular}{|c|c|c|c|c|c|c|}
\hline \multicolumn{2}{|c|}{ Annual average times of replacement } & 6 & 18 & 30 & 60 & 90 \\
\hline \multirow{3}{*}{ Average annual consumption } & 1 & 3 & 5 & 10 & 15 \\
\hline \multirow{3}{*}{ EOQ } & Total cost ( RMB million yuan ) & 0.97 & 2.92 & 4.32 & 7.51 & 9.98 \\
\cline { 2 - 8 } & Guarantee rate (\%) & 36.8 & 91.6 & 93.2 & 95.1 & 91.7 \\
\cline { 2 - 8 } & Quantity & 0 & 5 & 8 & 15 & 20 \\
\hline
\end{tabular}

It can be seen from the above table that when the annual average number of replacement is small, that is, the consumption is small, EOQ can be 0 , and the guarantee rate is in a low state; when the annual average number of replacement is gradually increasing, EOQ will also increase, and the guarantee rate will also increase and be at a high 
level; when the annual average number of replacement is further improved, the guarantee rate will fall to a certain extent.

Through analysis, the annual average times of replacement is a strong sensitive factor affecting EOQ.

\subsubsection{Unit price of aircraft parts procurement}

The change of purchase price of unit price of aircraft parts is considered according to its proportion in the original price, assuming that the change range of the proportion is from 0.1 to 10 , as shown in Table 4 . Under the condition that other indicators remain unchanged, this paper analyzes the impact of changes in the purchase price of aircraft parts on EOQ, as shown in Table 4 below.

Table 4 Effect of aircraft parts purchase price change on EOQ

\begin{tabular}{|c|c|c|c|c|c|c|c|c|c|c|}
\hline $\begin{array}{c}\text { Proportion of purchase unit price } \\
\text { to original price }\end{array}$ & 0.1 & 0.2 & 0.5 & 0.8 & 1 & 2 & 5 & 8 & 10 \\
\hline \multirow{5}{*}{ EOQ } & $\begin{array}{c}\text { Total cost( RMB million } \\
\text { yuan ) }\end{array}$ & 0.47 & 0.74 & 1.56 & 2.39 & 2.92 & 5.64 & 13.81 & 21.97 & 27.41 \\
\cline { 2 - 12 } & Guarantee rate (\%) & 91.6 & 91.6 & 91.6 & 91.6 & 91.6 & 91.6 & 91.6 & 91.6 & 91.6 \\
\cline { 2 - 11 } & Quantity & 5 & 5 & 5 & 5 & 5 & 5 & 5 & 5 & 5 \\
\hline
\end{tabular}

It can be seen from the above table that the change of aircraft parts purchase price has no significant impact on EOQ and guarantee rate level, but only the total cost changes. Therefore, the purchase price of aircraft parts is not sensitive to $\mathrm{EOQ}$.

\subsubsection{Unit shortage cost}

It is significant to analyze the influence of the change of shortage cost on EOQ. Through the analysis of the change of the ratio of unit shortage cost to aircraft part price, the ratio of unit shortage cost to aircraft part price in Section 5.1 is 0.5 , and the change range used here is from 0.1 to 10 .

Table 5 Effect of shortage cost on Effect of shortage cost on EOQ

\begin{tabular}{|c|c|c|c|c|c|c|c|c|c|c|c|}
\hline \multicolumn{2}{|c|}{$\begin{array}{l}\text { Ratio of unit shortage } \\
\text { cost to aircraft part price }\end{array}$} & 0.1 & 0.2 & 0.3 & 0.4 & 0.5 & 0.8 & 1 & 2 & 5 & 10 \\
\hline \multirow{3}{*}{$\begin{array}{l}\mathrm{E} \\
\mathrm{O} \\
\mathrm{Q}\end{array}$} & $\begin{array}{c}\text { Total cost( RMB million } \\
\text { yuan ) }\end{array}$ & 0.89 & 1.59 & 2.28 & 2.80 & 2.92 & 3.11 & 3.23 & 3.49 & 4.08 & 4.08 \\
\hline & Guarantee rate $(\%)$ & 5.0 & 5.0 & 5.0 & 81.5 & 91.6 & 91.6 & 91.6 & 96.6 & 99.6 & 99.6 \\
\hline & Quantity & 0 & 0 & 0 & 4 & 5 & 5 & 5 & 6 & 8 & 8 \\
\hline
\end{tabular}

It can be seen from the above table that EOQ and guarantee rate increase with the increase of shortage cost. In the case of low out of stock cost, EOQ can be zero, and the level of guarantee rate is low. At the same time, it can be seen that the unit shortage cost is a strong sensitive factor affecting EOQ of air material turnover parts.

\section{Conclusion}

The effective management and inventory control of aircraft parts has become an effective way for airlines to reduce operating costs and improve economic benefits, but the management level is not satisfactory. It is expected that this research can provide a new idea and method for the inventory control of aircraft turnover parts. This paper analyzes the factors that affect the economic order quantity of the aircraft turnover parts, divides the total cost of the turnover parts into depreciation cost, repair cost, inventory cost and shortage cost, and constructs the objective function of minimizing the total cost, so as to optimize the economic order quantity of the air material turnover parts. The 
feasibility of the method is verified by case analysis, and some meaningful conclusions are drawn through sensitivity analysis: annual replacement times and unit shortage cost are strong sensitive factors affecting economic order quantity, while purchase price is not.

\section{Acknowledgements}

This research was supported by National Natural Science Foundation of China (Grant No. 71403225).

\section{Reference}

[1] M.C. Mabini, A.H. Christer, "Controlling Multi-Indenture Repairable Inventories of Multiple Aircraft Parts", journal of the operational research society, vol.53, no.12, pp.1297-1307, 2002.

[2] R. Fritzsche, "Cost adjustment for single item pooling models using a dynamic failure rate: A calculation for the aircraft industry", Transportation Research Part E, vol.48, no.6, pp.1065-1079,2012.

[3] L. Sun, H Zuo, "Multi-echelon inventory optimal model of civil aircraft spare parts", In: Proceedings of 2010 Chinese Control and Decision Conference.2010.

[4] C. C. Sherbrooke. "Metric: A Multi-Echelon Technique for Recoverable Item Control", Operation research, vol.16, no.1, pp.122-141, 1968.

[5] R.J.I. Basten, M.C. van der Heijden,J.M.J. Schutten, "Joint optimization of level of repair analysis and spare parts stocks", European Journal of Operational Research, vol.222, no.3, pp.474-483,2012.

[6] H. Wong, G.J.van Houtum, D. Cattrysse, D. Van Oudheusden. "Multi-item spare parts systems with lateral transshipments and waiting time constraints", European Journal of Operational Research, vol.171, no.3, pp.1073-1091,2005.

[7] H. Rezaei, A. Baboli,M.K. Shahzad,R. Tonadre. "A new methodology to optimize target stock level for unpredictable demand of spare parts: A Case Study in Business Aircrafts' Industry", IFAC PapersOnLine, vol.51, no 11, pp.538-543, 2018.

[8] F. Costantino, G.Di Gravio, M. Tronci. "Multi-echelon, multi-indenture spare parts inventory control subject to system availability and budget constraints", Reliability Engineering and System Safety, vol.119, pp.95-101, 2013.

[9] R. Yan, "Research on Optimization of DH aviation material inventory management", Nanchang University, 2015.

[10] B. Lu, "Research on Optimization of SC airline's aviation material supply management", Shandong University of Finance and economics, 2016.

[11] J. Liang, "Research on Optimization of aircraft material inventory management of XX Airlines", Civil Aviation University of China, 2015.

[12] Y. Song , "Optimization and lean management of aviation material support in CA maintenance base", Zhejiang University of technology, 2013. 